\title{
Assessment of rooftop photovoltaic potentials at the urban level using publicly available geodata and image recognition techniques
}

\author{
Kai Mainzer ${ }^{\mathrm{a}, 1}$, Sven Killinger ${ }^{\mathrm{a}, \mathrm{b}}$, Russell McKenna ${ }^{\mathrm{a}}$, Wolf Fichtner ${ }^{\mathrm{a}}$ \\ ${ }^{a}$ Chair of Energy Economics, Karlsruhe Institute of Technology (KIT), 76187 Karlsruhe, Germany \\ ${ }^{b}$ Fraunhofer Institute for Solar Energy Systems ISE, 79110 Freiburg, Germany
}

\begin{abstract}
The local generation of renewable electricity through roof-mounted photovoltaic (PV) systems on buildings in urban areas provides huge potentials for the mitigation of greenhouse gas emissions. This contribution presents a new method to provide local decision makers with tools to assess the remaining PV potential within their respective communities. It allows highly detailed analyses without having to rely on $3 \mathrm{D}$ city models, which are often not available. This is achieved by a combination of publicly available geographical building data and aerial images that are analyzed using image recognition and machine learning approaches. The method also employs sophisticated algorithms for irradiance simulation and power generation that exhibit a higher accuracy than most existing PV potential studies. The method is demonstrated with an application to the city of Freiburg, for which a technical PV electricity generation potential of about $524 \mathrm{GWh} / \mathrm{a}$ is identified. A validation with a 3D city model shows that the correct roof azimuth can be determined with an accuracy of about $70 \%$ and existing solar installations can be detected with an accuracy of about $90 \%$. This demonstrates that the method can be employed for spatially and temporally detailed PV potential assessments in arbitrary urban areas when only public geographical building data is available instead of exact 3D city model data. Future work will focus on methodological improvements as well as on the integration of the method within an urban energy system modeling framework.
\end{abstract}

Keywords: $\mathrm{PV}$ potential, module orientation, image recognition, machine learning

\section{Introduction}

There is a worldwide consensus that greenhouse gas emissions should be substantially reduced over the next few decades in order to mitigate climate

\footnotetext{
*Chair for Energy Economics, Karlsruhe Institute of Technology (KIT), 76187 Karlsruhe, Germany. Tel.: +49721-608-44589.

Email address: kai.mainzer@kit.edu (Kai Mainzer) 12
}

5 change (IPCC, 2015). This can only be accom-

6 plished through a massive decarbonization of the energy system. One of the most important levers in this endeavor are combinations of energy efficiency measures and renewable energy resources in cities, which will have to play a crucial role in the energy transition (IEA, 2016).

In order to develop local schemes and make inJuly 4, 2017 
formed decisions for the transition to renewable en- ${ }_{47}$ ergies, policy makers need to be provided with accu- 48 rate information on the potential contribution from each of these measures on global as well as on re- ${ }_{50}$ gional and local levels.

The local generation of clean power through PV systems on building roofs, in particular, provides huge potentials that are usually economically viable. Compared to other available options, PV has higher public acceptance, partly because there is less competition for land or other resources.

The assessment of the (remaining) potential for power generation from $\mathrm{PV}$ is an important field of study. Methods and tools that enable local decision makers to assess $\mathrm{PV}$ potentials in their respective communities are of vital importance for the energy transition. The literature review in section 2 shows, however, that currently there are no tools available that allow local decision makers to assess these potentials in high detail and accuracy without first having to acquire large amounts of data. With this contribution, the authors intend to address this issue.

Since the requirements for detailed PV potential analyses usually include data that is not publicly available and, especially in smaller municipalities, can not be easily obtained, the objective of this contribution is to present a method for detailed urban PV potential assessment that relies solely on publicly available data and can be applied universally. The authors improve upon existing work as well as their previous publications (e.g. Mainzer et al. (2016)) in a number of points:

1. high-detailed, bottom-up PV potential analy- 78 sis in the absence of $3 \mathrm{D}$ model data

2. discrete number of actually installable modules instead of just the area

3. consideration of roof objects, e.g. chimneys and windows

4. exact irradiance simulation with high temporal resolution $(1 / 4$ hourly)

5. detailed, non-linear power generation model with consideration of temperature, module and inverter characteristics

6. consideration of already installed PV modules

The present literature on the subject is analyzed in section 2. In section 3 , all steps of the method that was developed are described in detail. Section 4 presents results from an example application of the method to the city of Freiburg, Germany. These results are further analyzed, validated and discussed. In section 5, the findings are concluded.

\section{Literature review}

Several publications have already addressed the problem of identifying PV potentials. The main steps in PV potential estimation methods include the assessment of the available area for PV modules, the simulation of solar irradiance on the tilted module surfaces and the calculation of produced electrical power from the irradiance on these modules. Martín-Chivelet (2016) provides an overview of different methodologies that are employed for each of these steps. As discussed in the following section, various levels of detail can be achieved with different approaches. In addition, Freitas et al. (2015) also provide an overview over solar potential in the 
urban environment with a focus on solar radiation 114 models.

For large-scale analyses, methods based on sta- 116 tistical data, e.g. building databases, are commonly 117 used. Schallenberg-Rodríguez (2013) provides a re- 118 view of methods for the assessment of the available 119 roof area using statistical building data and roof ${ }_{120}$ utilization factors, the calculation of monthly so- 121 lar radiation values on inclined surfaces and yearly 122 electricity production. The scale of assessments us- ${ }_{123}$ ing these methods is rather large, e.g. Schallenberg- ${ }_{124}$ Rodríguez (2013) applies them to the Canary Is- 125 lands and Defaix et al. (2012) assess the PV poten- 126 tial in the EU-27. Due to data availability, however, ${ }_{127}$ the detail of these approaches is limited, which re- ${ }_{128}$ sults in a low spatial and temporal resolution of the ${ }_{129}$ assessed potentials. Other approaches combine sta- 130 tistical methods with geographical information sys- 131 tems (GIS) to increase the spatial resolution, e.g. 132 Mainzer et al. (2014) assess the PV potentials for 133 Germany on a municipal level.

If more detail and higher spatial resolutions ${ }_{135}$ are required, bottom-up methods that rely on 3D ${ }_{136}$ model data are common. For instance, Romero ${ }_{137}$ Rodríguez et al. (2017) use a 3D city model to cal- ${ }_{138}$ culate the total roof area and received solar irradi- ${ }_{139}$ ance for the German County district Ludwigsburg. ${ }_{140}$ Combined with factors for the share of usable roof ${ }_{141}$ area and technical efficiency as well as economic ${ }_{142}$ constraints, they are able to calculate the techni- ${ }_{143}$ cal and economic PV potential at an urban scale in ${ }_{144}$ high resolution.

Although 3D models are becoming increasingly common, in most cases they are not freely available or, especially for smaller municipalities, not available at all. Additionally, the heterogeneity of data formats is a hindrance to using them for arbitrary regions within the same model framework. The methods used to create 3D city models differ, but usually either Light Detection and Ranging (LiDAR, e.g. Srećković et al. (2016); Brito et al. (2012); Nguyen and Pearce (2012); Jakubiec and Reinhart (2013)) or stereophotogrammetry (e.g. Theodoridou et al. (2012); Jo and Otanicar (2011); Wittmann et al. (1997)) are used. Both methods can provide very detailed 3D models, but both also require significant investments in terms of money and time. Surveying flights in order to obtain the data and manual labor in order to create the 3D model are required. Similar methods that rely on $3 \mathrm{D}$ models are employed in commercial applications $^{1}$, which can be used to estimate the PV yield for single buildings. These approaches are in some cases very detailed, however, they do not allow the assessment for larger regions and they are usually available only in certain regions.

Although some of the above mentioned methods are very detailed, they still use many simplifications that could easily be improved upon. For example, most studies apply fixed utilization factors to consider the fact that in most cases, the available roof area can only partially be used for PV installations due to obstructions like chimneys or windows. They also calculate the number of modules that can be installed on the roof area with a simple packing factor, instead of calculating how many PV modules could actually fit inside the respective roof shape.

\footnotetext{
${ }^{1}$ One example is a cooperation of E.ON and Google, available at www.eon-solar.de.
} 
Examples for these simplifications can be found 181 in Martín-Chivelet (2016); Schallenberg-Rodríguez 182 (2013); Defaix et al. (2012); Singh and Banerjee 183 (2015); Mainzer et al. (2014); Fath et al. (2015); 184 Mavromatidis et al. (2015) and others. Most pub- 185 lished methods also apply very simple models to 186 calculate the produced electricity from the received 187 irradiance, usually by applying a fixed module effi- 188 ciency and performance ratio of the system, instead 189 of considering the non-linear effects of temperature, 190 module type, inverter utilization etc. This is a well- 191 known field of study, though, and more sophisti- 192 cated algorithms are available and can easily be 193 implemented, see e.g. Drews et al. (2007) for mod- 194 ule temperature modeling, Huld et al. (2010) for 195 module efficiency calculation and Macêdo and Zilles (2007) for inverter efficiencies.

With the higher detail that improvements in 197 these areas could provide, the results could be bet- 198 ter employed in studies that examine the integra- 199 tion of PV in the energy system. For example, 200 Killinger et al. (2015) determine the optimal in- 201 vestment in differently oriented PV systems in the 202 context of four German regions with regard to their 203 ability to match the local demand, reduce strain on 204 the power grid or replace fossil power production. 205 On a larger scale, Mainzer et al. (2014) analyze how much of the available PV potential in each German 206 municipality could be exploited before electricity 207 would have to be fed back into the national grid. 208 The integration of PV into the distribution net- 209 work infrastructure is analyzed by Srećković et al. 210 (2016) in a case study for Maribor, Slovenia and by ${ }_{211}$ Wegertseder et al. (2016) for Concepción, Chile. ${ }_{212}$ Currently, there are no methods available that ${ }_{213}$ can provide $\mathrm{PV}$ potential assessments with a high spatial resolution when $3 \mathrm{D}$ model data is not available. However, a number of approaches that deal with the problem of acquiring geographical data that is not (publicly) available have been published in the past. Taubenböck (2007) presents a method to estimate the height of buildings based on an analysis of shadow lengths in satellite images. Assouline et al. (2017) use machine learning (support vector machines) to spatially extrapolate weather variables, and to estimate roof characteristics based on training data from 42 communes in Switzerland. Miyazaki et al. (2016) use neural networks to automatically derive building locations from Bing Map aerial images

Bergamasco and Asinari (2011) present a methodology that estimates the suitability of a roof based on pixel colors and brightnesses. Hazelhoff and de With (2011) attempt to automatically detect buildings with a gable roof in rural areas. Both of these approaches could be used in the context of PV potential estimation, however, both also rely on very-high-resolution aerial images, which have been provided by local authorities in connection with a specific project.

All of the reviewed approaches either lack the level of detail that would be required to use the assessed PV potentials, e.g. in energy system models to support the creation of energy concepts, or they provide high detail but depend on existing 3D city models, which are often not available. None of these approaches can easily be applied in another region without manually acquiring additional data. 


\section{Methodology}

The approach that is used to assess the remaining economic potential in a given region is conducted within nine distinct steps, as shown in Figure 1.

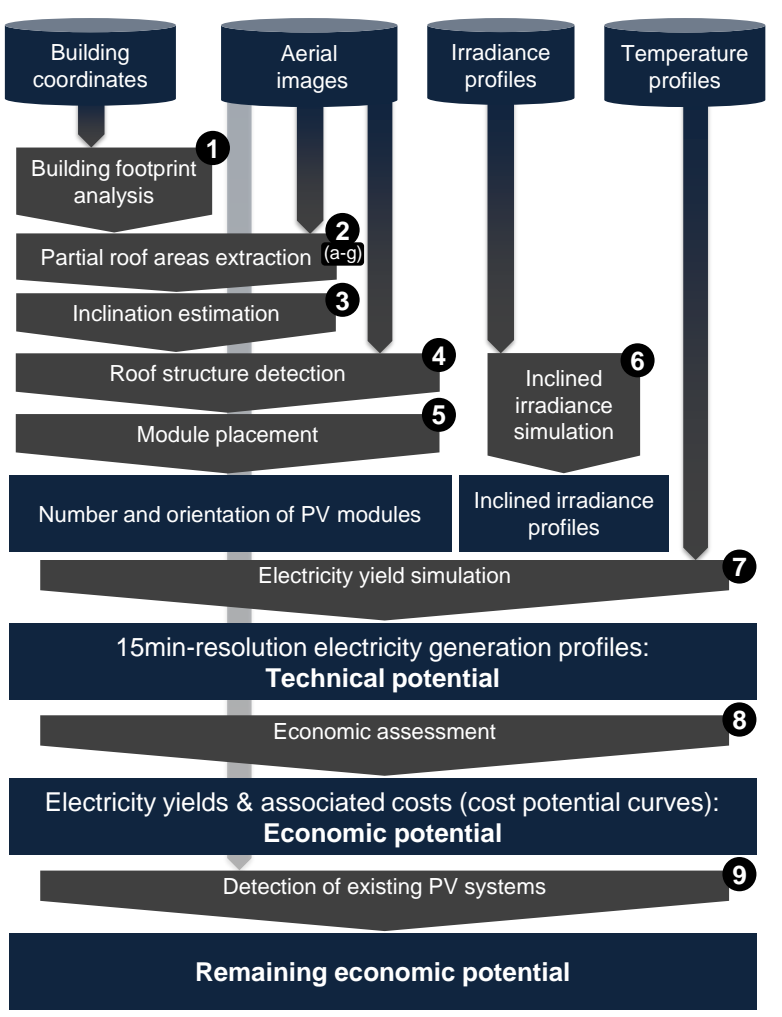

Figure 1: Overview of the presented approach.

while other methods that provide the same level of detail usually rely on commercial data (c.f. section 2). This implies that this method can be applied in any region where OpenStreetMap data, aerial or satellite images, as well as irradiance and temperature data are available.

All steps are fully automated and implemented within a larger Java model framework intended for the analysis and optimization of urban energy systems: the Renewable Energy and Energy Efficiency Analysis and System Optimization ( $\left.\mathrm{RE}^{3} \mathrm{ASON}\right)$ model (McKenna et al., 2016). Figure D.12 shows the graphical user interface of this model for the PV potential assessment, which allows all relevant parameters to be adjusted as needed for applications in other regions.

In the subsections 3.1 to 3.9 , each step of the method is described in detail. All of these steps are conducted for each single building in the analyzed region. Throughout these methods, a number of techno-economic assumptions are used - these are summarized in Appendix A, Table A.1.

\subsection{Building footprint assessment}

First of all, the sizes and exact locations of all buildings in the analyzed area have to be retrieved. This is done by querying the OpenStreetMap database (OpenStreetMap-Contributors, 2017) for paths and relations with the 'building' tag, using the Overpass Turbo $\mathrm{API}^{2}$. OpenStreetMap typically does not provide any information on the height or the roof shape of buildings - only the area of the building footprint. These building footprints are

\footnotetext{
${ }^{2}$ See http://overpass-turbo.eu/.
} 
later used to calculate the sizes and orientations of 295 partial roof areas.

Additionally, the azimuth angles of the building 297 outlines (i.e. the building walls) are determined as 298 a basis for the angles of possible roof ridge lines, as 299 these are usually parallel to the building walls. Very 300 large buildings (with more than $3,000 \mathrm{~m}^{2}$ ground 301 area) are assumed to be office blocks, factories or 302 similar with flat roofs. For flat roofs, the steps 2303 and 3 are skipped.

\subsection{Partial roof areas extraction}

For each building, the orthographic aerial image ${ }^{307}$ covering the buildings' (roof) area is retrieved from ${ }^{308}$ Bing Maps (Microsoft, 2016) and clipped to the cor- ${ }^{309}$ rect shape, using the building footprint. Next, a ${ }^{310}$ number of image processing algorithms are applied ${ }^{311}$ to the image in order to retrieve the roof's ridge line ${ }^{312}$ and deduce the orientations of partial roof areas (as ${ }^{313}$ illustrated in Figure 2):

a) A bilateral filter is applied to reduce noise ${ }_{316}$ while preserving the edges of the image.

b) A color filter creates a black-and-white version ${ }_{318}$ of the image: For each pixel, the weighted aver- ${ }_{319}$ age intensity is calculated by adding the values ${ }_{320}$ for the red, green and blue color components, ${ }_{321}$ whereby empirically derived weights $\left(0.75,0,{ }_{322}\right.$ and 0.25 for the channels red, green and blue, ${ }_{323}$ respectively) are applied to each color.

c) Histogram equalization is applied to the image. 325 This method enhances the overall contrast of ${ }_{326}$ the image by spreading out the most frequent ${ }_{327}$ intensity values to create a more uniform distri- 328 bution. This makes it easier to distinguish, e.g. 329 two separate partial roof areas in cases when they have similar color and brightness.

d) The Canny Edge algorithm (Canny, 1986) is employed to extract the edges, i.e. areas with significant local intensity changes, from the image. This is done by identifying and connecting local maxima of intensity gradients in the horizontal and vertical directions of the image. These edges usually represent noticeable structures like walls, chimneys, windows, or what's most interesting in this use case - the roof ridge.

e) The Hough Transformation algorithm (Duda and Hart, 1972) is applied to detect straight lines in the previously found edges. In short, this is achieved by iterating over the parameter space of line equations in the polar coordinate system for each pixel and identifying those lines that most pixels lie on.

f) These lines are further analyzed by subsequently applying logical filters in order to determine which line (if any) represents the roofs' ridge line. This involves deleting lines that are very close to the building walls (e.g. drain pipes or parts of the building outline that do not exactly align with the aerial image) and lines that are not parallel to one of the buildings' walls. Additionally, lines that are interrupted by, e.g. shadows, are merged into a single line.

If, after applying these filters, there are still multiple lines left, the weighted sum of the criteria length and brightness difference are used to determine which line is most probably the correct ridge line. Here, length denotes a normalized measure of line length (with 0: no line, 

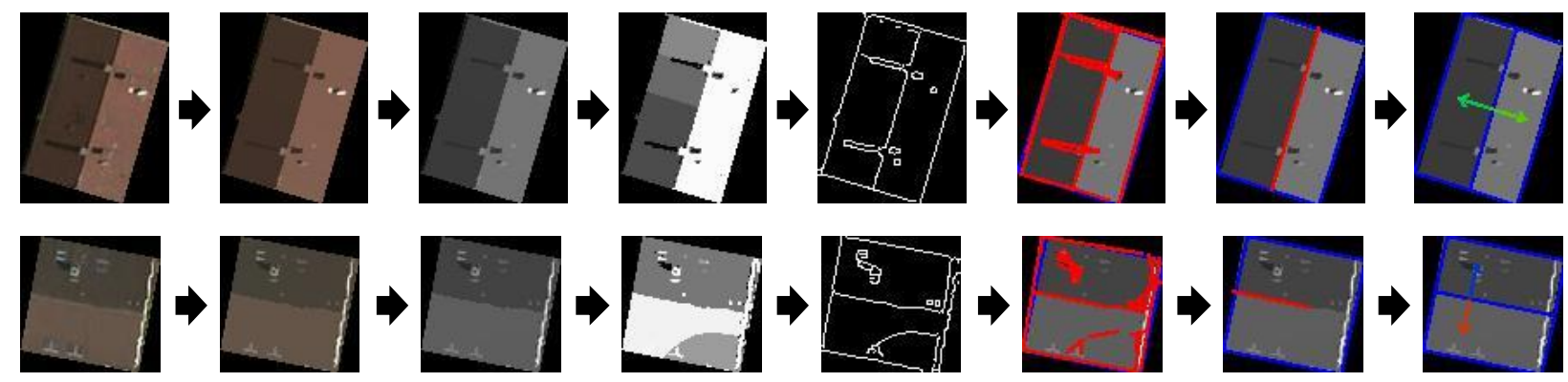

(e)

(f)

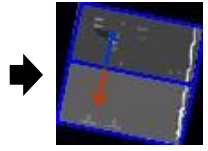

(g)

Figure 2: Process of roof ridge line detection on the aerial image for two different buildings: (a) bilateral filtering, (b) color filtering, (c) histogram equalization, (d) Canny Edge Detection, (e) Hough Line Transformation, (f) logical filtering, (g) calculation of azimuth. The hue of the azimuth indicator arrow ranges from red (south) over yellow and green to blue (north). Source: Own depiction with image data from Bing Maps (Microsoft, 2016).

1: longest line), while the brightness difference 351 is calculated by splitting the image in half with ${ }_{352}$ each line and calculating the average bright- 353 ness in both halves of the image - large differ- ${ }_{354}$ ences indicate partial roof areas with different 355 lighting conditions (0: no brightness difference, 356 1: greatest brightness difference).

g) If the ridge line is found, it can be used to de- 358 duce the partial roof areas (which face in dif- 359 ferent azimuth directions) of the building.

The selection of algorithms as well as their parameters and the order in which they are applied ${ }_{362}$ have been determined by experimentation and refined during the validation process. Some parameters are adjusted dynamically, e.g. when no ridge lines are found, the thresholds for the Canny and Hough algorithms are reduced iteratively. Most of the image processing algorithms are provided through the open computer vision library OpenCV (Bradski, 2000), algorithmic descriptions can be found, for example, in Burger and Burge $(2016)^{3}$.

\footnotetext{
${ }^{3}$ See chapter 4.5 in that book for histogram equalization,
}

In some cases (for about $27 \%$ of the analyzed buildings), no valid ridge line can be found. This can happen, e.g. when the contrast is too weak to find the ridge line, when the building is not (yet) captured by the aerial image, or when it has a flat roof and thus no ridge exists. These buildings are either classified into having a flat roof (see next subsection) or divided into partial areas using a fallback method, which splits the building in halves, assuming that the longest building wall is parallel to the roof ridge.

\subsection{Inclination estimation}

The second parameter of a roofs' orientation is given by its tilt. On flat roofs, PV modules are usually mounted with stands, while on tilted roofs, they are mounted in the same angle as the roof.

However, aerial images provide only a single perspective and thus contain no information on the height of buildings. Since this makes it difficult to extract the tilt, a normal distribution function

chapter 8 for hough transformation, chapter 16 for canny edge detection and chapter 17 for bilateral filtering. 
about a mean of $37^{\circ}$, with a standard deviation of 395 $15^{\circ}$ is used to estimate the tilt for each roof. These 396 parameters have been derived by fitting a normal 397 distribution function to tilted roofs from LiDAR data in Baden-Wuerttemberg (c.f. Figure 3).

If no ridge line could be identified on a roof, that could be due to the building having a flat roof. Based on the assumption that, overall, about $9 \%$ of buildings should have flat roofs (LUBW, 2012), these buildings are then classified into whether having a flat roof or not by a random draw.

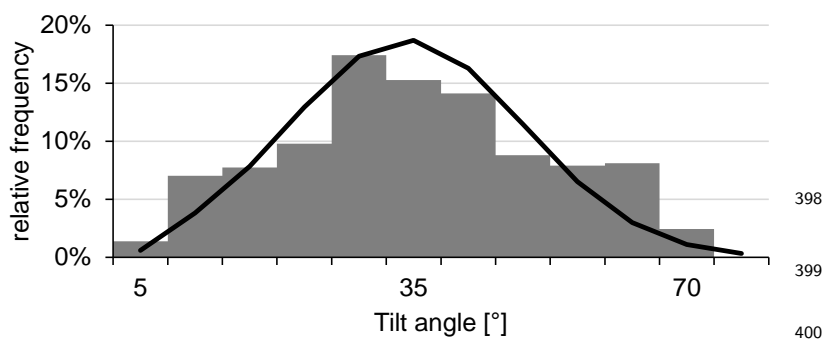

Figure 3: Histogram of tilted roof angles for 3,002,943 build- 401 ings in Baden-Wuerttemberg (grey bars) and the assumed 402 normal distribution function $(N(37 ; 15)$, black line). Source: Own depiction based on LiDAR data from LUBW (2012).

\subsection{Roof structure detection}

In most cases, only part of the roof area can be ${ }_{407}$ used for PV applications, since most roofs contain 408 structures like chimneys, windows, etc. that limit 409 the available area. In previous PV potential studies, 410 this fact has typically been accounted for by sub- 411 tracting a fixed share of the roof area. The method ${ }_{412}$ presented here uses the aerial image to identify 413 these roof structures. To achieve this, methods for 414 contour detection (Suzuki and Abe, 1985) and poly- 415 gon approximation (Douglas and Peucker, 1973) are 416 employed in order to identify possible objects on the ${ }_{417}$ partial roof areas. All identified objects that fulfill ${ }_{418}$ certain criteria (based on size and shape) are subtracted from the usable area. An example of the roof structure detection can be seen in Figure 4.
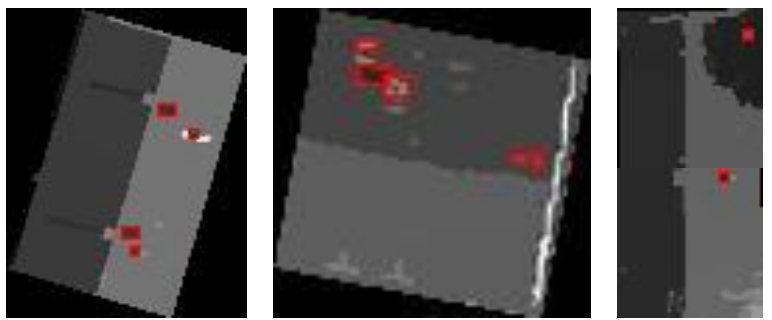

Figure 4: Examples for roof structure detection. Red markers are drawn around detected structures. Source: Own depiction with image data from Bing Maps (Microsoft, 2016).

\subsection{Module placement}

In the next step, the number of modules that could be fitted into the previously determined roof areas needs to be determined. This is done by an algorithm that incrementally iterates over the usable area and fits as many PV modules as possible within each partial roof area. For slanted roofs, the modules are assumed to be mounted in the same angle as the roof itself and consequently no significant distance has to be left between them $(10 \mathrm{~cm}$ are used). The result of such a module placement can be seen in Figure 5 .

For flat roofs, it is assumed that mounting systems are used to position the PV modules facing south, with a $30^{\circ}$ tilt angle. In order to prevent mutual shadowing, a distance of twice the modules' height is kept free between adjacent rows of modules. These parameters provide a good tradeoff, for middle-European latitudes, between optimal yield and losses due to dirt and mutual shadowing (Quaschning, 2013). 

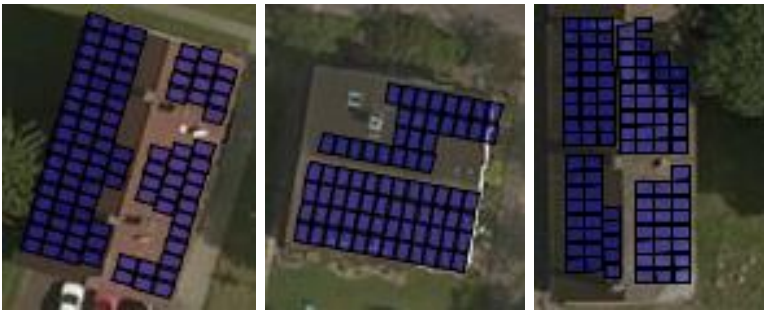

\subsection{Irradiance simulation}

Figure 5: Examples for module placement, considering size, 448 azimuth, tilt and shape of the available roof areas, as well ${ }_{449}$ as roof structures. Source: Own depiction with image data from Bing Maps (Microsoft, 2016).
In many cases, this estimate of installable PV ${ }_{453}$ modules might be too optimistic. Not all obstacles ${ }_{454}$ on a roof can be identified from aerial images, and ${ }_{455}$ some buildings are not suited for PV installations ${ }_{456}$ due to structural constraints. Other buildings can ${ }_{457}$ not be used since they are protected as historical ${ }_{458}$ landmark buildings, which in Germany applies to ${ }_{459}$ about $3.5 \%$ of buildings (Diefenbach et al., 2010). ${ }_{460}$

Without 3D model data, it is also not possible to ${ }^{461}$ consider the effect of shading from other buildings, ${ }^{462}$ which has been shown to reduce the PV potential by ${ }^{463}$ $14 \%$ to $21 \%$ (without/with consideration of obsta- ${ }^{464}$ cles on the roof respectively) in densely populated 465 areas (Takebayashi et al., 2015). Shading from trees 466 or the surrounding landscape could further reduce ${ }^{467}$ the potential.

Consequently, all of these factors combined are accounted for by reducing the PV potential that has been calculated so far by $30 \%$. Nowak (2002) uses a reduction factor of $40 \%$ to compensate for such factors, but since that method does not explicitly consider obstacles on the roof as done here ${ }_{473}$ (see section 3.4), a somewhat smaller value seems 474 to be justified.
In order to calculate the electricity that could be generated from these modules, the amount of irradiance they receive has to be simulated. The global irradiance on tilted module planes consists of contributions from direct, diffuse, and reflective components and can be calculated by using the irradiance on a horizontal plane and applying trigonometric calculations.

To calculate the sun's position at the location of interest over the course of a year, the Algorithm 3 as described by Grena (2012) is used. The calculated position is then combined with irradiance data (direct and diffuse irradiance on a horizontal plane, provided by the Copernicus Atmosphere Monitoring Service (CAMS) European Commission (2017)) in order to simulate the direct, diffuse and reflected irradiance components. Literature provides several approaches to doing this, the methods that were used in this paper are described in detail in Appendix B.

Since these calculations are quite resource intensive, they can not be performed for each possible combination of tilt and azimuth. Instead, each roof is classified into one of 144 discrete orientation classes (16 azimuth and 9 tilt classes). For each of these classes, the received global irradiance is calculated in 15 minute timesteps over the course of one year.

3.7. Electricity yield simulation

The electricity output from a PV system depends not only on the received global irradiance, but also 475 on the module temperature as well as technical 
characteristics of the modules and the power in- 505 verter.

In this work, this is considered by simulating the 507 efficiency of the modules and the inverter system 508 as a function of ambient temperature, irradiance 509 and load factor. For the technical characteristics, a 510 given module and inverter type (c.f. Appendix A, 511 Table A.1) is assumed. The details of the employed 512 methods are described in Appendix D.

\subsection{Economic assessment}

In the last step, an economic analysis is conducted. A good indicator for economic feasibility is provided by the levelized costs of electricity ( $L C O E$, in $€ / \mathrm{kWh}$ ), as defined e.g. by Branker et al. (2011). These can be calculated by dividing the total discounted costs (investment plus operational costs) of a system over its lifetime $L T$ by the total discounted energy generation over the same period:

$$
L C O E=\frac{n \cdot I_{m}+\sum_{t=0}^{L T} \frac{n \cdot I_{m} \cdot r_{o c}}{(1+i)^{t}}}{\sum_{t=0}^{L T} \frac{W_{0} \cdot(1-d)^{t}}{(1+i)^{t}}},
$$

with $W_{0}$ in $\mathrm{kWh}$ being the amount of electric ity produced in the first year, $n$ the number of PV modules, $r_{o c}$ the operational costs share of investment and $t$ the year. The definitions and assumptions of further parameters are given in Appendix

\section{A, Table A.1.}

By aggregating the possible yearly electricity generation and sorting by ascending $L C O E$, a costpotential curve (CPC) can be generated from these calculations. An example can be seen in Figure 8 .

The economic potential can now be derived by defining a maximum $L C O E$ and selecting only those PV installations with lower costs. However, when evaluating technologies only by $L C O E$, it should be mentioned that these fail to consider aspects like generation profiles, flexibility and external effects. Additionally, the economic viability of PV installations is also dependent on further individual factors, e.g. the share of self consumption.

514 515 516 517 518 519 520 521 522

\footnotetext{
${ }^{4}$ Using the Open-Source Deep-Learning Java library Deeplearning $4 \mathrm{j}$.
} 
supervised learning technique called backpropaga- 568 tion with 2,934 manually labeled images of build- 569 ing roofs (of which $80 \%$ were used for training and 570 $20 \%$ for validation), belonging either to the cate- 571 gory ' $P V$ ' or 'no $P V$ '.

The so-trained CNN is then used to predict for 573 each analyzed building the probability that its roof 574 is already equipped with a PV installation. If the 575 predicted probability exceeds 90\%, the associated 576 roof area is considered as being already occupied 577 and its potential is then subtracted from the total 578 potential.

\section{Results and discussion}

The previous section has demonstrated how the method assesses the potential for PV installations in any region by analyzing the roof areas of all buildings and calculating the electricity that could be produced as well as the associated costs.

In this section, the example application of this method to the city of Freiburg, Germany is demonstrated. After showing the aggregated results as well as more detailed results for individual districts (subsection 4.1), the findings are validated by comparing the determined azimuths with 3D model data (subsection 4.2) and evaluating the accuracy of the neural network for the detection of existing PV systems (subsection 4.3).

\subsection{Application to Freiburg, Germany}

Due to the availability of a 3D model (Stabsstelle Geodatenmanagement, 2016), the city of Freiburg was used as an application, so that the roof parameterization could be validated. But, since the 580 method relies solely on publicly available data, it can be applied almost anywhere. It can be used to analyze individual buildings, city districts, or large-scale urban areas. Due to the necessary assumptions about the tilt angle distribution, the uncertainty for individual buildings is generally higher than for larger aggregation levels. There is no absolute limit to the size of the analyzed region, it is mainly restricted by the required computational effort: for Freiburg, the analysis took about 30 hours and $80 \mathrm{~GB}$ of $\mathrm{RAM}^{5}$

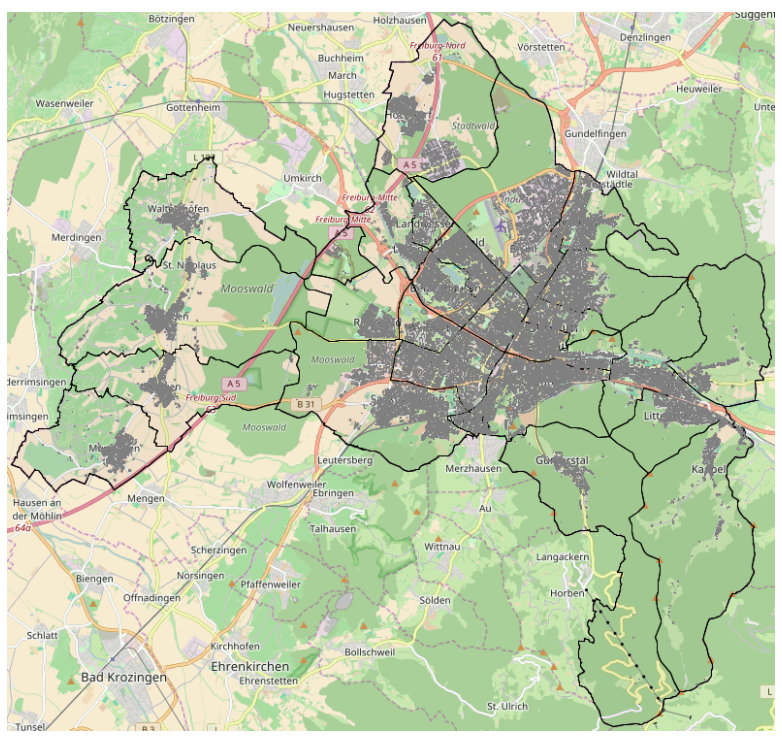

Figure 6: The analyzed area of Freiburg, divided into 28 districts, with 49,573 buildings in total. Buildings are highlighted in gray. Source: Own depiction with map data from OpenStreetMap-Contributors (2017).

The result from this analysis can be seen in Figure 6 and Figure 8 (left). For the 49,573 buildings

\footnotetext{
${ }^{5} \mathrm{~A}$ machine with 12 Intel Xeon E-1650 $3.2 \mathrm{GHz}$ cores was used for the analysis. Memory demand is mainly due to a lot of information, e.g. the exact coordinates for each positioned PV module, being saved during the analysis to enable graphic visualizations as well as quality checks.
} 
in Freiburg, a technical electricity generation poten- 616 tial of $524 \mathrm{GWh} / \mathrm{a}$ was found, of which $85 \mathrm{GWh} / \mathrm{a}{ }_{617}$ has been classified as already exploited. The $L C O E{ }_{618}$ for these potentials range from 9 to $29 € \mathrm{ct} / \mathrm{kWh} .{ }_{619}$ It should be mentioned that, contrary to many 620 other studies, roofs with suboptimal orientations 621 have not been excluded from this analysis a priori 622 - these are represented by those parts of the cost- ${ }_{623}$ potential-curve that exhibit the highest costs. The 624 CPC could, however, be used to easily derive an 625 economic potential by simply defining a maximum 626 $L C O E$ threshold.

The results can be accessed via a graphical user ${ }_{628}$ interface that enables analyzing the city as a whole 629 (Figure 6), looking into single districts (Figure 7) 630 or even buildings (Figure 5).

A closer look at the results on a district level 632 reveals the added value of this method over ap- 633 proaches that rely purely on statistical data. Fig- 634 ure 7 highlights two of the analyzed districts which 635 differ in the layout of their road network: in the district Mooswald (left area), most of the streets are ${ }^{636}$ laid out in a diagonal pattern. Since building foot- 637 prints are often oriented in parallel to the streets, 638 a large share of roofs which face in less optimal 639 directions (e.g. south-west instead of direct south) 640 can be expected. In Herdern, on the other hand, 641 the street direction layout is quite heterogeneous, ${ }_{642}$ so the whole range of possible azimuth directions is 643 expected.

The model results confirm this: an analysis of 645 the average deviation from south (of the better ori- ${ }_{646}$ ented partial area from each building, respectively) ${ }_{647}$ shows that in Herdern, the distribution is quite 648 heterogeneous (mean $46^{\circ}$, standard deviation $30^{\circ}$ ). ${ }_{649}$
In Mooswald, in contrast, it is very concentrated (mean $45^{\circ}$, standard deviation $5^{\circ}$ ). This is also reflected in the resulting cost-potential curves (Figure 8, right): for Mooswald (red) the curve is not as evenly distributed as for Herdern (blue) and exhibits less distinctive steps, since many azimuths are not present.

This difference is caused only by different distributions of azimuth directions in the two districts, which was correctly identified by the approach presented here. Hence, this example highlights why it is important to consider azimuth directions in PV potential estimations in high detail: even if the available roof areas might be comparable in two different regions, the distribution of azimuth directions has a large impact on the yearly sum as well as the costs of the resulting electricity generation. This is similarly important for other applications, e.g. for regional PV power generation simulations (as shown in Killinger et al. (2017)).

\subsection{Evaluation of the azimuth determination}

In order to evaluate the accuracy of the parameterization of roof azimuths in the model, the results have been compared with a 3D model of Freiburg, containing 191,335 partial roof areas (Figure 9).

For the sake of this comparison, it is assumed that the 3D model is $100 \%$ correct, although the authors are aware that it actually does contain a number of errors which could lead to false results. It was generated by using the LiDAR-method with a limited spatial resolution. The fact that, in many cases, the 3D model has partitioned a roof into many small partial roof areas leads to certain challenges when comparing the azimuths between both 


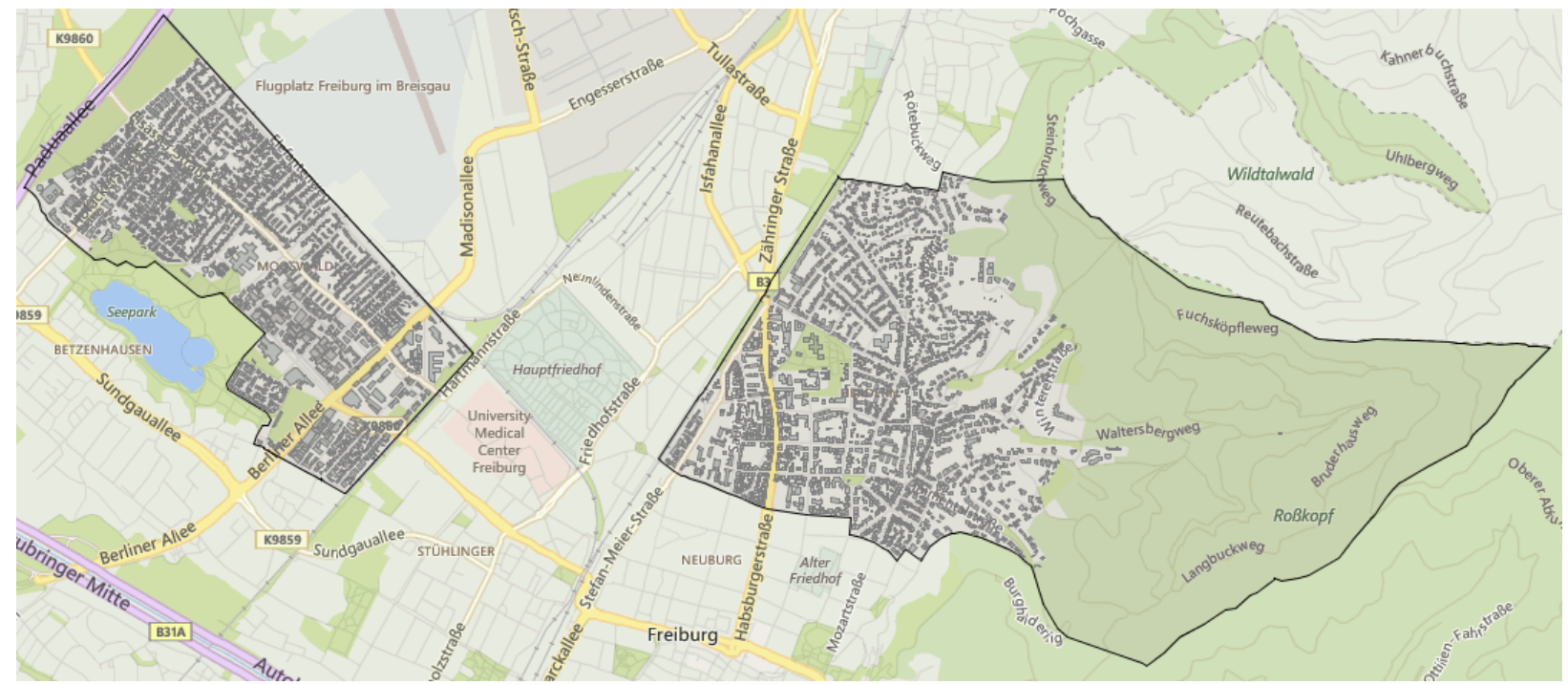

Figure 7: The districts Mooswald (left area) and Herdern (right area) in Freiburg, Germany. Source: Own depiction with map data from Bing Maps (Microsoft, 2016).

models. This results in the fact that only about half 669 of the total number of buildings could be compared 670 by geographically matching the roof areas.

Figure 10 shows the result of comparing azimuths $\quad 672$ from the 3D model with those from the model pre- ${ }_{673}$ sented here for all 26,412 buildings that could be ${ }_{674}$ geographically matched. From the high concentra- 675 tion along the line that bisects the $\mathrm{x}$ - and $\mathrm{y}$-axis, it ${ }_{676}$ can clearly be seen that in most cases, the model results agree.

Most errors occur due to a deviation of $\pm 90^{\circ 6}$, which occurred for about $20 \%$ of the compared roofs. This is owed to the fact that building walls are usually in a right angle with each other and in these cases, the method chose the wrong ridge line which was parallel to one of the building walls. There is also a small cluster (about $5 \%$ of the compared roofs, not noticeable from the graphic) of errors around $\pm 45^{\circ}$. This is probably due to the al-

${ }^{6}$ Which is equivalent to a deviation of $\pm 270^{\circ}$. gorithm being fooled by multiple ridge lines, e.g. on hip roofs.

The errors are quite symmetric, which means that the algorithm does not favor a deviation in a certain direction. This implies that it does not produce any systematic error, which could compromise the results in terms of power generation noticeably, if present.

The density plot illustrates that certain orientations (namely $20^{\circ}, 110^{\circ}, 200^{\circ}$ and $290^{\circ}$ ) are more frequent than others in Freiburg, presumably due to the general road patterns. This demonstrates the importance of the consideration of the actual azimuth directions, since neglecting these specific distributions could result in significant deviations in power prediction, as also shown in Killinger et al. (2017).

Most of the errors that were observed can be attributed to poor image quality (e.g. outdated imagery, images with low resolution or weak contrasts) 

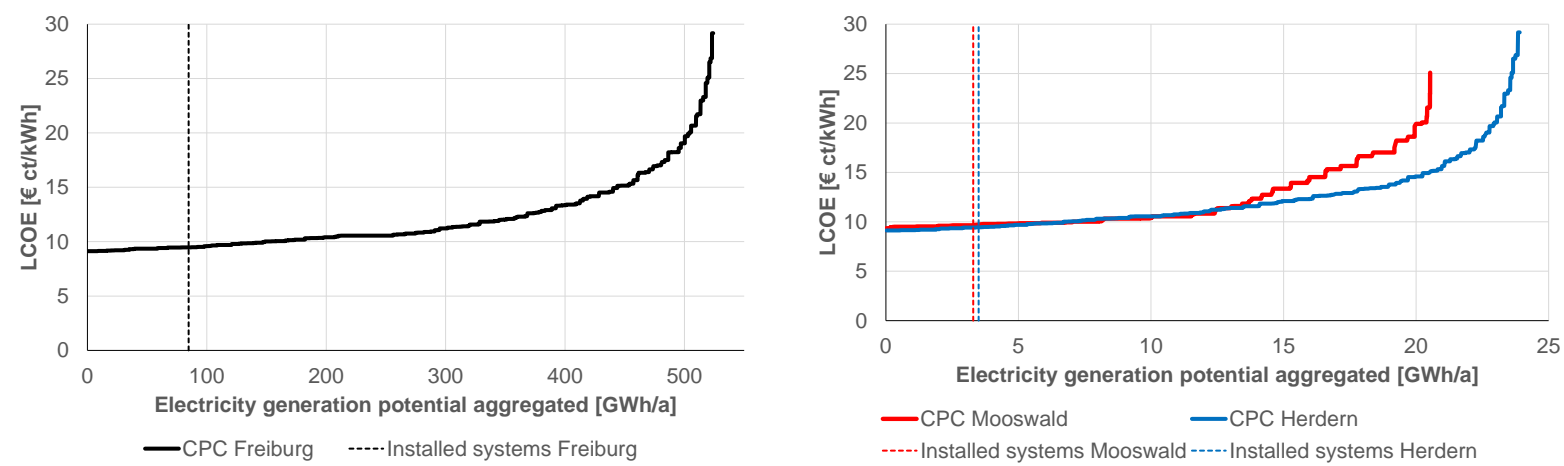

Figure 8: Cost-potential curve for the whole city of Freiburg (left) as well as the districts Mooswald and Herdern (both right). Source: Own depiction.

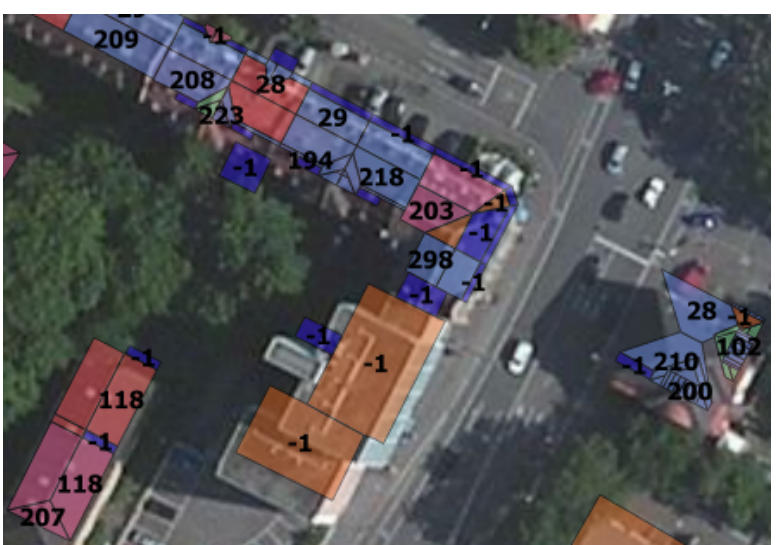

Figure 9: An excerpt from the model data that was used for evaluating the model. The colors indicate different roof types, the numbers indicate the azimuth of the respective roof areas (0 is north, 180 south, -1 refers to flat roofs). Source: Own depiction with map data from Bing Maps Microsoft (2016) and Stabsstelle Geodatenmanagement (2016).

and when structures on the roof (e.g. windows or existing PV modules) have been falsely identified as the roof's ridge line.

From these validations, it can be concluded that ${ }_{697}$ the method for azimuth determination has a fail- 698 ure rate (wrong ridge line chosen due to shadows, 699 roof windows, building walls, or similar) of less than 700

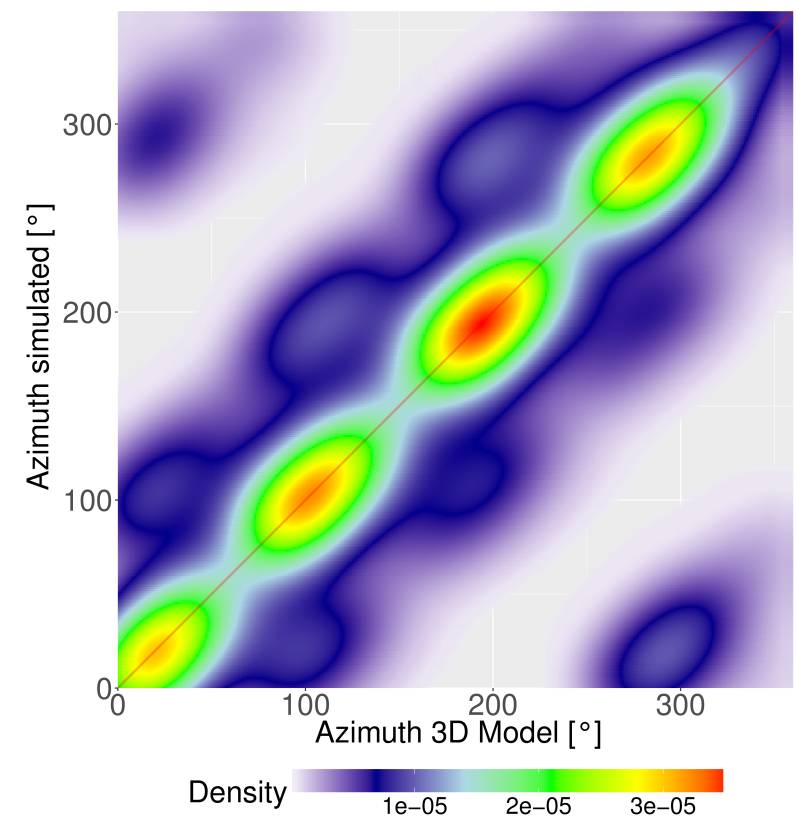

Figure 10: Density plot of the simulated azimuth from more than 52,000 partial roofs in comparison with azimuth derived from the 3D model.

$30 \%$. These errors are assumed to be mainly manifested in the profile of the power predictions and only to a smaller extent in the yearly sum of power production, since the aggregation tends to balance out these errors. 


\subsection{Evaluation of the PV systems detection}

The neural network for PV system detection has ${ }^{731}$ been trained for about 50 iterations with the full ${ }^{732}$ dataset of 2,934 images. After this process, an ac- ${ }^{733}$ curacy $^{7}$ of $90.97 \%$ could be achieved, i.e. the major- ${ }^{734}$ ity of buildings could be correctly categorized into ${ }^{735}$ having an existing PV installation or not.

Since the training data was retrieved from only ${ }^{737}$ a limited number of geographically distinct regions ${ }^{738}$ in Germany $^{8}$, the accuracy is not guaranteed to be ${ }^{739}$ the same in each application, e.g. due to variations 740 in image quality, lighting conditions, etc. However, ${ }^{741}$ by manually checking excerpts from the results (see ${ }^{742}$ Figure 11), it can be confirmed that the recognition is correct in most cases.

In the analysis of Freiburg, roof areas that cor- ${ }^{744}$ respond to about $85 \mathrm{GWh}$ of the identified technical potential have been classified as already exploited. The German renewable energy plants reg- ${ }^{747}$ ister (DGS, 01.08.2014) states an installed capacity ${ }^{74}$ of 35 GWh/a in 2014 for Freiburg. The discrepancy can be explained by the fact that in the model, the ${ }^{750}$ whole potential of a roof area is regarded as ex- ${ }^{751}$ ploited when an existing PV system is detected, ${ }^{752}$ while in reality this is often not the case (e.g. the ${ }^{753}$ top-right building in Figure 11). From manual ex- ${ }^{754}$ aminations of over 200 sample images with existing ${ }^{755}$ PV installations, the authors conclude that in many ${ }^{756}$ cases, only about 30 to $80 \%$ of the available area is ${ }^{757}$

${ }^{7}$ Accuracy is defined as $\frac{\text { (TruePositives }+ \text { TrueNegatives })}{(\text { Positives }+ \text { Negatives })}{ }^{759}$ Other common indicators for binary classification quality are 760 Precision (here: 91.91\%), Recall (90.96\%) and the F1 Score 761 $(91.08 \%)$.

${ }^{8}$ Aerial images from Karlsruhe, Feuchtwangen and Mies- ${ }^{762}$ bach were used as training data. actually exploited. Additionally, the image quality does not allow to differentiate between PV modules and solar thermal installations. This is correct in the sense that these roof areas are classified as exploited, but not, as assumed by the model, through PV installations. Additionally, the aerial imagery is usually more recent and may show many PV systems that have not yet been considered in the plant register data in 2014. Despite these uncertainties, the validations lead to the conclusion that the detection of existing solar installations can successfully be accomplished with the proposed machine learning approach.

\subsection{Critical reflection and outlook}

With the method described here, the problem of assessing highly detailed PV potential estimations when no $3 \mathrm{D}$ data (e.g. from LiDAR) is available has successfully been resolved. However, quite a number of uncertainties and challenges remain with regard to input data, methodology and evaluation, which are discussed in this section.

Some challenges are related to the input data that is used: the age as well as the quality of OpenStreetMap data can be quite heterogeneous, in some cases very high and in other cases quite low, incomplete or outdated. To a certain extent, the same applies to the aerial imagery, for which the resolution as well as the age can vary between different regions.

Compared to approaches that rely on 3D models, the data this methodology uses inherently prohibits the consideration of shadowing from other buildings or the environment. This might be addressed in the future by using additional data sources, should they 


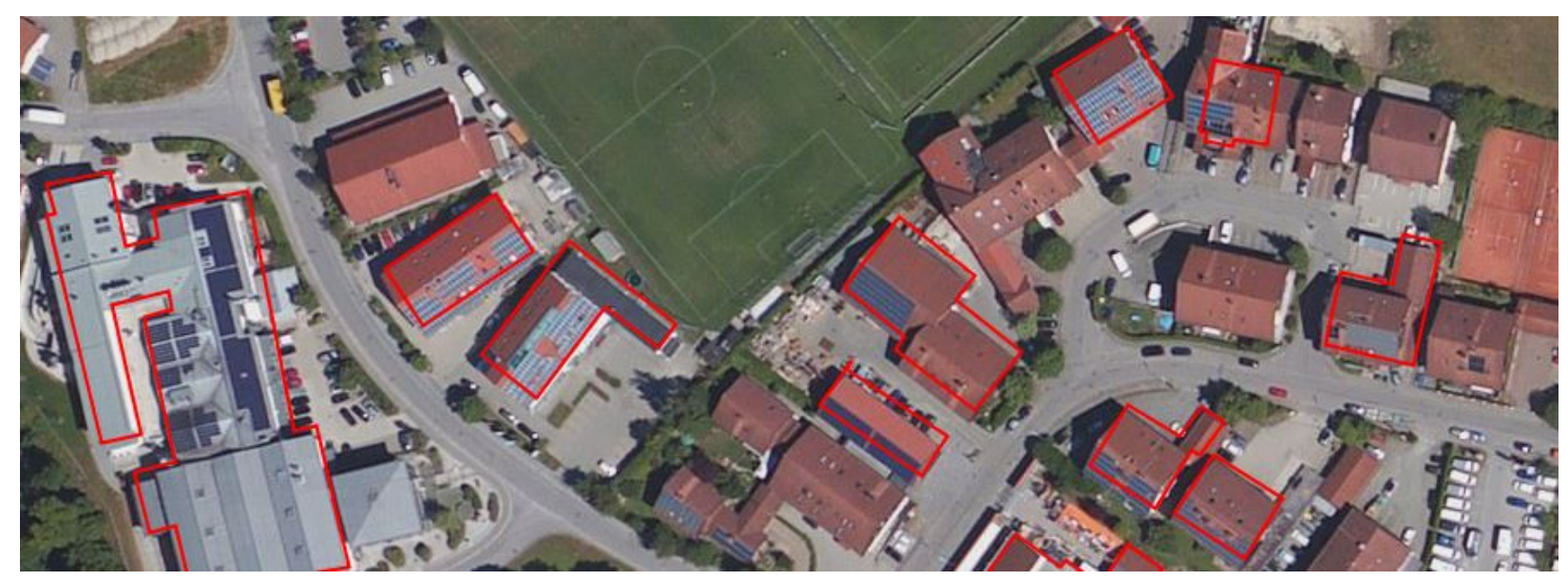

Figure 11: Automated detection of existing PV systems: roofs that have been classified by the neural network into having PV modules installed are highlighted red. Source: Own depiction with image data from Bing Maps (Microsoft, 2016).

become available.

The method itself could also be improved in a ${ }^{787}$ number of ways. First of all, the image-based roof 788 area extraction is currently only able to analyze 789 simple building geometries with gable/ridge roofs. 790 In cases of more complex building geometries, e.g. 791 T-shaped buildings, a fallback method is applied. ${ }^{792}$ This issue is currently being addressed by an ap- 793 proach using image segmentation algorithms and is 794 a subject for future work.

As compared to methods that employ 3D city 796 models, this method is not able to assess the tilt of 797 building roofs, as this can not easily be extracted 798 from aerial imagery. The current approach is an 799 estimation of tilt using an empirical distribution 800 function. This could be improved in future work ${ }_{801}$ by analyzing the brightness differences between roof ${ }_{802}$ areas and correlating them with empirical training 803 data (possibly also by employing a machine learn- 804 ing approach). It is currently unknown, however, 805 whether this approach could work reliably.

Since this method relies purely on two dimen- 807 sional data, it does currently not allow for the consideration of vertical structures for PV applications (often referred to as Building Integrated Photovoltaics, BIPV). These options, which could be applied to building walls or even to some of the roof structures discussed in section 3, step 4, could potentially further extend the overall PV potential.

The steps in this method that rely on image recognition techniques are meant to approximate the human capabilities of evaluating the suitability of a roof for $\mathrm{PV}$ applications, based on its aerial image. The approach presented here is not yet on par with human accuracy, so parts of the method could possibly be improved by e.g. applying additional filters or different algorithms.

The presented method is currently quite resource intensive, which has prevented large-scale (e.g. national) applications so far. Several improvements could reduce the computational effort. Memory demand could be reduced by discarding details, e.g. retaining only the number of installable modules per roof instead of their exact locations in memory. 
Additionally, the computing time could be reduced 843 by parallelization.

Several uncertainties remain along the PV power 845 production simulation chain. Gueymard (2008, 846 2009 ) evaluates these uncertainties with respect to 847 irradiance modeling for solar engineering applica- 848 tions, whereas Hansen et al. (2013), Krauter et al. ${ }_{849}$ (2008), and Kreifels et al. (2016) present a sensi- 850 tivity analysis along the whole simulation chain in- 851 cluding both irradiance and PV power modeling. 852 Despite these uncertainties, however, the methods 853 used within this paper are still significantly more 854 detailed than the ones employed in comparable 855 studies (see section 2).

The detection of existing PV systems can be ${ }_{857}$ fooled, e.g. when the image quality is bad. It should 858 be mentioned that (qualitatively) better artificial 859 neural network architectures for image classifica- 860 tion than the one used here are available today 861 (and have partially been tested during the devel- 862 opment of this methodology). However, these tend 863 to be more complex, which usually leads to an in- 864 crease in memory consumption and runtime, which 865 quickly becomes relevant in large-scale applications with thousands of buildings.

The evaluation itself is also prone to errors. Since there is no proven correct data on $\mathrm{PV}$ potentials, 867 data that is also uncertain has to be used for val- 868 idation. For each deviation found, it remains un- 869 clear whether it is due to an error in the method or 870 the data that it was validated against. The lack of 871 good data for validation, however, again highlights 872 the need for methods such as the one developed in 873 this work.

When the method is applied to other regions, 875 some changes to the employed parameters might be required. Local knowledge can be used to adjust the roof tilt distribution function, the mounting angle and row distances for flat roofs, as well as other parameters. The overall reduction factor can be adjusted if it is known that many or high trees, heterogeneous building heights, narrow streets or similar factors that limit the PV potential are present.

Finally, the presented method does not account for the integration of the $\mathrm{PV}$ electricity into the local energy system. This tends to be overly optimistic, as additional costs for network upgrade and storage capacities might result from this integration. More detailed economic implications from a system-point-of-view could be derived by employing the method presented here within an urban energy system modeling framework. This could allow not only the consideration of the determined $L C O E$ for PV systems, but also the temporal structure of their electricity generation profiles and the combination with other renewable energies and energy efficiency measures. Such analyses will be part of future work and presented within forthcoming publications.

\section{Conclusion}

In this contribution, a new method for the assessment of rooftop PV potentials at the urban level has been presented. This method can be used to conduct PV potential analyses in high detail and in many regions of the world. It uses publicly available geographical building data and aerial images in combination with image recognition techniques to derive the size and orientation of partial roof areas without having to rely on $3 \mathrm{D}$ model data. 
Compared to existing methods for PV poten- 911 tial assessment, it improves upon several shortcom- 912 ings. Instead of applying roof utilization factors, 913 this method calculates the discrete number of PV 914 modules that could be installed on each roof, con- 915 sidering the roof shape as well as objects like chim- 916 neys or windows that could prevent PV installa- 917 tions. The method includes an exact irradiance 918 simulation with high temporal resolution as well as 919 a detailed power generation model, which consid- 920 ers the non-linear effects of temperature, module 921 and inverter characteristics to calculate the tech- 922 nical PV electricity generation potential. By relat- ${ }_{923}$ ing this to the respective investments and operating 924 costs, highly detailed cost-potential-curves for arbi- 925 trary urban areas can be calculated. Additionally, 926 the aerial images are analyzed by a Convolutional 927 Neural Network, trained to detect existing PV mod- 928 ules on building roofs, which enables the model to 929 account for the share of $\mathrm{PV}$ potential already ex- 930 ploited.

The method has then been applied to the Ger- ${ }_{932}$ man city of Freiburg for demonstration and valida- 933 tion. A technical electricity generation potential of 934 $524 \mathrm{GWh} /$ a could be identified, of which $85 \mathrm{GWh} / \mathrm{a} 935$ was classified as already exploited. The applica- 936 tion has demonstrated that the method allows a ${ }_{937}$ good representation of roof azimuths that often fol- 938 low distinct road patterns. The comparison with 939 an existing 3D city model has shown a good agree- 940 ment between the respective azimuths. Thus it can ${ }_{941}$ be concluded that the presented methodology could 942 improve the quality and extent of PV potential as- ${ }_{943}$ sessments for urban areas in the absence of exten- 944 sive data.
This method can be employed in a number of use cases. As mentioned in section 1, PV potential estimations can provide local decision makers with critical information, e.g., for designing energy concepts. Due to the use of public data, this method can be applied in arbitrary cities worldwide, although variations in the OpenStreetMap building data or Bing imagery quality may limit its use, e.g. in some remote regions. Nonetheless, this methods enables even smaller municipalities that have no access to 3D city models to get detailed information about their local potentials. With the high detail of results this method offers, it can ultimately be used to identify the PV potential as an input for energy system models that rely on a high spatial and temporal resolution. The method has already been applied in the development of an energy master plan for a German municipality (McKenna et al., 2016), where the exact assessment of the total amount as well as the temporal structure of possible electricity generation enabled an optimal integration of PV in the urban energy system. The method could also be used to determine the current and future distribution of PV panel orientations and thus the predicted $\mathrm{PV}$ electricity generation in power distribution networks, which is an important information for network operators (see Killinger et al. (2017)). The automated detection of existing PV systems could also be used for fraud detection in renewable energy subsidy schemes, where solar operators claim feedin tariffs for installations that have not (yet) been built.

Future work will focus on improving the method for better recognition of complex roof shapes, exploring methods to derive the roof tilt from aerial 
images and further validating the algorithm with 982 larger sets of 3D city model data. Finally, the ${ }^{983}$ method will be employed within an urban energy system modeling framework in order to consider the ${ }_{986}$ optimal integration of PV into the local energy sys- 987 tem.

\section{Acknowledgments}

The authors gratefully acknowledge the finan- 993 cial support of the BMBF for the project Wet- ${ }^{994}$ tbewerb Energieeffiziente Stadt (03SF0415B) and ${ }_{996}^{995}$ the Nagelschneider Foundation. The authors would 997 also like to thank David Schlund for his contribu- 998 tions to earlier versions of this method.

\section{References}

Assouline, D., Mohajeri, N., Scartezzini, J.L., 2017. Quan- 1004 tifying rooftop photovoltaic solar energy potential: $A_{1005}$ machine learning approach. Solar Energy 141, 278-296. 1006 doi:10.1016/j. solener.2016.11.045.

Bergamasco, L., Asinari, P., 2011. Scalable methodology for 1008 the photovoltaic solar energy potential assessment based ${ }_{1009}$ on available roof surface area: Further improvements by 1010 ortho-image analysis and application to Turin (Italy). So- 1011 lar Energy 85, 2741-2756. doi:10.1016/j.solener.2011. 1012 08.010 .

Bradski, G., 2000. The OpenCV library. Dr. Dobb's Journal 1014 of Software Tools .

Branker, K., Pathak, M., Pearce, J.M., 2011. A review of 1016 solar photovoltaic levelized cost of electricity. Renewable 1017 and Sustainable Energy Reviews 15, 4470-4482. doi:10. 1018 1016/j.rser.2011.07.104.

Brito, M., Gomes, N., Santos, T., Tenedório, J., 2012. Pho- 1020 tovoltaic potential in a Lisbon suburb using LiDAR data. 1021 Solar Energy 86, 283-288. doi:10.1016/j.solener.2011. 1022 09.031.

1023 Bührke, T., Wengenmayr, R., 2011. Erneuerbare En- 1024 ergie: Konzepte für die Energiewende. Wiley-VCH Verlag
GmbH \& Co. KGaA, Weinheim, Germany. doi:10.1002/ 9783527646906 .

Burger, W., Burge, M.J., 2016. Digital image processing: An algorithmic introduction using Java. Texts in computer science.

Canny, J., 1986. A Computational Approach to Edge Detection. IEEE Transactions on Pattern Analysis and Machine Intelligence PAMI-8, 679-698. doi:10.1109/TPAMI.1986. 4767851.

Defaix, P.R., van Sark, W., Worrell, E., de Visser, E., 2012. Technical potential for photovoltaics on buildings in the EU-27. Solar Energy 86, 2644-2653. doi:10.1016/j. solener.2012.06.007.

DGS, 01.08.2014. EnergyMap - Auf dem Weg zu 100\% EE - Der Datenbestand. URL: http://www. energymap.info/ download.html.

Diefenbach, N., Cischinsky, H., Rodenfels, M., 2010. Datenbasis Gebäudebestand: Datenerhebung zur energetischen Qualität und zu den Modernisierungstrends im deutschen Wohngebäudebestand.

Douglas, D., Peucker, T., 1973. Algorithms for the reduction of the number of points required to represent a digitized line or its caricature. Cartographica: The International Journal for Geographic Information and Geovisualization 10, 112-122. doi:10.3138/FM57-6770-U75U-7727.

Drews, A., de Keizer, A.C., Beyer, H.G., Lorenz, E., Betcke, J., van Sark, W., Heydenreich, W., Wiemken, E., Stettler, S., Toggweiler, P., Bofinger, S., Schneider, M., Heilscher, G., Heinemann, D., 2007. Monitoring and remote failure detection of grid-connected PV systems based on satellite observations. Solar Energy 81, 548-564. doi:10.1016/j. solener.2006.06.019.

Duda, R.O., Hart, P.E., 1972. Use of the Hough transformation to detect lines and curves in pictures. Communications of the ACM 15, 11-15. doi:10.1145/361237.361242.

European Commission, 2017. Copernicus Atmosphere Monitoring Service (CAMS) radiation service. URL: http://www.soda-pro.com/web-services/radiation/ cams-radiation-service.

Fath, K., Stengel, J., Sprenger, W., Wilson, H.R., Schultmann, F., Kuhn, T.E., 2015. A method for predicting the economic potential of (building-integrated) photovoltaics in urban areas based on hourly Radiance simulations. So- 
lar Energy 116, 357-370. doi:10.1016/j.solener.2015. 1068 03.023.

Freitas, S., Catita, C., Redweik, P., Brito, M.C., 2015. Mod- 1070 elling solar potential in the urban environment: State-of- 1071 the-art review. Renewable and Sustainable Energy Re- 1072 views 41,915-931. doi:10.1016/j.rser.2014.08.060. 1073

Grena, R., 2012. Five new algorithms for the computation 1074 of sun position from 2010 to 2110 . Solar Energy 86, 1323- 1075 1337. doi:10.1016/j.solener.2012.01.024.

Gueymard, C., 2008. From global horizontal to global tilted 1077 irradiance: How accurate are solar energy engineering pre- 1078 dictions in practice?, Solar 2008 Conf., San Diego, CA, 1079 American Solar Energy Society.

Gueymard, C.A., 2009. Direct and indirect uncertainties 1081 in the prediction of tilted irradiance for solar engineering 1082 applications. Solar Energy 83, 432-444. doi:10.1016/j. 1083 solener.2008.11.004.

Hansen, C., Pohl, A., Jordan, D., 2013. Uncertainty and sen- 1085 sitivity analysis for photovoltaic system modeling. Tech- 1086 nical Report. Sandia National Laboratories. Albuquerque, 1087 New Mexico and Livermore, California.

Hazelhoff, L., de With, P., 2011. Localization of build- 1089 ings with a gable roof in very-high-resolution aerial im- 1090 ages. Visual Information Processing and Communication 1091 II doi:10.1117/12.873748.

He, K., Zhang, X., Ren, S., Sun, J., 2015. Delving deep into 1093 rectifiers: Surpassing human-level performance on Ima- 1094 geNet classification, in: 2015 IEEE International Confer- 1095 ence on Computer Vision (ICCV), pp. 1026-1034. doi:10. 1096 1109/ICCV.2015.123.

Huld, T., Gottschalg, R., Beyer, H.G., Topič, M., 2010. 1098 Mapping the performance of PV modules, effects of mod- 1099 ule type and data averaging. Solar Energy 84, 324-338. 1100 doi:10.1016/j.solener. 2009.12.002.

IEA, 2016. Energy technology perspectives 2016: Towards 1102 sustainable urban energy systems. URL: http://www. 1103 iea.org/etp/etp2016/.

IPCC (Ed.), 2015. Climate change 2014: Synthesis report. 1105 Intergovernmental Panel on Climate Change, Geneva, 1106 Switzerland

Jakubiec, J.A., Reinhart, C.F., 2013. A method for pre- 1108 dicting city-wide electricity gains from photovoltaic pan- 1109 els based on LiDAR and GIS data combined with hourly 1110
Daysim simulations. Solar Energy 93, 127-143. doi:10. 1016/j.solener.2013.03.022.

Jo, J.H., Otanicar, T.P., 2011. A hierarchical methodology for the mesoscale assessment of building integrated roof solar energy systems. Renewable Energy 36, 2992-3000. doi:10.1016/j.renene.2011.03.038.

Killinger, S., Braam, F., Müller, B., Wille-Haussmann, B., McKenna, R., 2016. Projection of power generation between differently-oriented PV systems. Solar Energy 136, 153-165. doi:10.1016/j.solener.2016.06.075.

Killinger, S., Burckhardt, L., McKenna, R., Fichtner, W., 2015. GIS-basierte Parametrierung der Modulorientierung von Photovoltaik-Anlagen, in: VDI Wissensforum - Optimierung in der Energiewirtschaft, Düsseldorf, Germany. pp. 131-136.

Killinger, S., Guthke, P., Semmig, A., Muller, B., WilleHaussmann, B., Fichtner, W., 2017. Upscaling PV power considering module orientations. IEEE Journal of Photovoltaics 7, 941-944. doi:10.1109/JPHOTOV. 2017. 2684908. Krauter, S., Grunow, P., Preiss, A., Rindert, S., Ferretti, N., 2008. Inaccuracies of input data relevant for PV yield prediction: PVSC '08 ; 11 - 16 May 2008, San Diego, California ; conference proceedings , 1-5doi:10.1109/PVSC. 2008.4922866 .

Kreifels, N., Killinger, S., Fischer, D., Wille-Haussmann, B., 2016. Uncertainty and error analysis of calculation procedures for PV self-consumption and its significance to investment decisions, in: 13th European Energy Market Conference, Porto, Portugal.

Krizhevsky, A., Sutskever, I., Hinton, G.E., 2012. ImageNet Classification with Deep Convolutional Neural Networks, in: Advances in Neural Information Processing Systems, pp. 1097-1105.

Lorenz, E., Scheidsteger, T., Hurka, J., Heinemann, D., Kurz, C., 2011. Regional PV power prediction for improved grid integration. Progress in Photovoltaics: Research and Applications 19, 757-771. doi:10.1002/pip. 1033.

LUBW, 2012. Potenzialatlas Erneuerbare Energien. URL: http://www .energieatlas-bw.de/.

Macêdo, W.N., Zilles, R., 2007. Operational results of gridconnected photovoltaic system with different inverter's sizing factors (ISF). Progress in Photovoltaics: Research 
and Applications 15, 337-352. doi:10.1002/pip.740. 1154 Mainzer, K., Fath, K., McKenna, R., Stengel, J., Fichtner, 1155 W., Schultmann, F., 2014. A high-resolution determina- 1156 tion of the technical potential for residential-roof-mounted 1157 photovoltaic systems in Germany. Solar Energy 105, 715- 1158 731. doi:10.1016/j.solener.2014.04.015.

Mainzer, K., Schlund, D., Killinger, S., McKenna, R., 1160 Fichtner, W., 2016. Rooftop PV potential estimations: 1161 Automated orthographic satellite image recognition 1162 based on publicly available data, in: Proceedings of 1163 EU PVSEC. URL: http://www.eupvsec-proceedings. 1164 com/proceedings?fulltext=mainzer\&paper=38595, $\quad 1165$ doi:10.4229/EUPVSEC20162016-7E0.2.3.

Martín-Chivelet, N., 2016. Photovoltaic potential and land- 1167 use estimation methodology. Energy 94, 233-242. doi:10. 1168 1016/j.energy.2015.10.108.

Mavromatidis, G., Orehounig, K., Carmeliet, J., 2015. Eval- 1170 uation of photovoltaic integration potential in a village. 1171 Solar Energy 121, 152-168. doi:10.1016/j.solener.2015. 1172 03.044 .

McKenna, R., Bertsch, V., Mainzer, K., Fichtner, W., 2016. 1174 Combining local preferences with multi-criteria decision 1175 analysis and linear optimisation to develop feasible en- 1176 ergy concepts in small communities, in: Working paper 1177 series in production and energy. Institut für Industriebe- 1178 triebslehre und Industrielle Produktion (IIP), Karlsruhe. 1179 volume 16. URL: http://www.iip.kit.edu/downloads/ 1180 WP16_Nov16.pdf.

Microsoft, 2016. Bing Maps. URL: http://www.maps.bing. 1182 com.

Miyazaki, H., Kuwata, K., Ohira, W., Guo, Z., Shao, X., 1184 $\mathrm{Xu}$, Y., Shibasaki, R., 2016. Development of an auto- 1185 mated system for building detection from high-resolution 1186 satellite images, in: 2016 Fourth International Workshop 1187 on Earth Observation and Remote Sensing Applications. 1188

Nguyen, H.T., Pearce, J.M., 2012. Incorporating shading 1189 losses in solar photovoltaic potential assessment at the 1190 municipal scale. Solar Energy 86, 1245-1260. doi:10. 1191 1016/j.solener. 2012.01.017.

Nowak, S., 2002. Potential for Building Integrated Photo- 1193 voltaics: Achievable levels of electricity from photovoltaic 1194 roofs and facades: methodology, case studies, rules of 1195 thumb and determination of the potential of building inte- 1196 grated photovoltaics for selected countries: Report IEAPVPS T7-4. URL: www.iea-pvps.org/index.php?id=9\& eID=dam_frontend_push\&doc $I D=394$.

OpenStreetMap-Contributors, 2017. OpenStreetMap. URL: http://www .openstreetmap.org/.

Perez, R., Ineichen, P., Seals, R., Michalsky, J., Stewart, R., 1990. Modeling daylight availability and irradiance components from direct and global irradiance. Solar Energy 44, 271-289. doi:10.1016/0038-092X (90) 90055-H.

Pickering, K.A., 2002. The southern limit of the ancient star catalog and the commentary of Hipparchos. DIO, The International Journal of Scientific History 12, 3-27.

Quaschning, V., 2013. Regenerative Energiesysteme: Technologie - Berechnung - Simulation. 8 ed., Carl Hanser Verlag, München.

Romero Rodríguez, L., Duminil, E., Sánchez Ramos, J., Eicker, U., 2017. Assessment of the photovoltaic potential at urban level based on 3D city models: A case study and new methodological approach. Solar Energy 146, 264-275. doi:10.1016/j . solener. 2017.02.043.

Schallenberg-Rodríguez, J., 2013. Photovoltaic technoeconomical potential on roofs in regions and islands: The case of the Canary Islands. Methodological review and methodology proposal. Renewable and Sustainable Energy Reviews 20, 219-239. doi:10.1016/j.rser.2012.11. 078.

Schubert, G., 2012. Modellierung der stündlichen Photovoltaik- und Windstromeinspeisung in Europa, in: 12. Symposium Energieinnovation, Graz, Austria.

Singh, R., Banerjee, R., 2015. Estimation of rooftop solar photovoltaic potential of a city. Solar Energy 115, 589602. doi:10.1016/j.solener.2015.03.016.

SoDa, 2017. MERRA 2 re-analysis web service. URL: http: //www.soda-pro.com/web-services/meteo-data/merra. Srećković, N., Lukač, N., Žalik, B., Štumberger, G., 2016. Determining roof surfaces suitable for the installation of PV (photovoltaic) systems, based on LiDAR (Light Detection And Ranging) data, pyranometer measurements, and distribution network configuration. Energy 96, 404414. doi:10.1016/j.energy.2015.12.078.

Stabsstelle Geodatenmanagement, $2016 . \quad$ LOD2 Daten von Freiburg. URL: https://www. service-bw.de/organisationseinheit/-/sbw-oe/ 
Stabsstelle+Geodatenmanagement+Stadt+Freiburg+im+ ${ }_{123}$ Breisgau-6008924-organisationseinheit-0.

Suzuki, S., Abe, K., 1985. Topological structural analysis of digitized binary images by border following. Computer Vision, Graphics, and Image Processing PII: 0734189X(85)90016-7, 32-46. doi:10.1016/0734-189X (85) 90016-7

Takebayashi, H., Ishii, E., Moriyama, M., Sakaki, A., Nakajima, S., Ueda, H., 2015. Study to examine the potential for solar energy utilization based on the relationship between urban morphology and solar radiation gain on building rooftops and wall surfaces. Solar Energy 119, 362-369. doi:10.1016/j.solener.2015.05.039.

Taubenböck, H., 2007. Vulnerabilitätsabschätzung der erdbebengefährdeten Megacity Istanbul mit Methoden der Fernerkundung. Dissertation. Bayerische Julius-

Maximilians Universität Würzburg. Würzburg. 1243

Theodoridou, I., Karteris, M., Mallinis, G., Papadopou- 1244 los, A.M., Hegger, M., 2012. Assessment of retrofitting measures and solar systems' potential in urban areas using Geographical Information Systems: Application to ${ }^{1246}$ a Mediterranean city. Renewable and Sustainable En- 1247 ergy Reviews 16, 6239-6261. doi:10.1016/j.rser.2012. ${ }_{1248}$ 03.075 .

Wegertseder, P., Lund, P., Mikkola, J., García Alvarado, R., 2016. Combining solar resource mapping and energy ${ }^{1250}$ system integration methods for realistic valuation of ur- 1251 ban solar energy potential. Solar Energy 135, 325-336. ${ }_{1252}$ doi:10.1016/j.solener.2016.05.061.

Wirth, H., 2016. Recent facts about photovoltaics in Germany. URL: https://www. ise.fraunhofer.de/en/publications/studies/ recent-facts-about-pv-in-germany.html.

Wittmann, H., Bajons, P., Doneus, M., Friesinger, H., ${ }^{1254}$ 1997. Identification of roof areas suited for solar en- 1255 ergy conversion systems. Renewable Energy 11, 25-36. doi:10.1016/S0960-1481(96)00116-4.

Yang, D., Ye, Z., Nobre, A.M., Du, H., Walsh, W.M., Lim, L.I., Reindl, T., 2014. Bidirectional irradiance transposition based on the Perez model. Solar Energy 110, 768-780. doi:10.1016/j.solener.2014.10.006

\section{Appendix A. Assumptions in the presented approach}

See Table A.1.

\section{Appendix B. Transposition of irradiance}

The global irradiance in plane of array $G_{c}$ consists of contributions from direct, diffuse, and reflective irradiance,

$$
G_{c}=B_{c}+D_{c}+R_{c} \text {. }
$$

Within this section, several formulas are presented to transpose the direct and diffuse irradiance on the horizontal plane into the parametrized module orientation as described in Killinger et al. (2016).

The direct irradiance in plane of array $B_{c}$ can be calculated from the direct irradiance on the horizontal plane $B_{h}$ by using trigonometric relations. All angles are measured in radians if not otherwise explicitly defined. $B_{c}$ is limited to a positive range and defined as

$$
B_{c}=B_{h} \cdot \frac{\cos \theta}{\cos \theta_{Z}} \cdot(1-y) .
$$

Here, $\theta$ denotes the incidence angle, i.e. the angle of a module's surface normal to the position of the sun.

$\theta$ can be expressed in terms of the tilt angle $\beta$, zenith angle $\theta_{Z}$ and azimuth angles $\left(\alpha_{\text {poa }}, \alpha_{Z}\right)$ of a module orientation and the position of the sun, respectively,

$$
\begin{aligned}
\cos \theta= & \cos \theta_{Z} \cdot \sin \beta+\sin \theta_{Z} \\
& \cdot \cos \beta \cdot \cos \left(\alpha_{Z}-\alpha_{\text {poa }}\right) .
\end{aligned}
$$


Techno-economic assumptions

\begin{tabular}{l|l||l|l}
\hline Criteria & Assumptions & Criteria & Assumptions \\
\hline Classes of tilt & 9 & Distance between modules & $0.1 \mathrm{~m}$ \\
Classes of azimuth & 16 & Nominal power of modules & $235 \mathrm{~W}$ \\
Flat roof share & $9 \%$ & Module lifetime $L T$ & $25 \mathrm{a}$ \\
Threshold value for footprint & $3000 \mathrm{~m}^{2}$ & Minimal power per area & $1000 \mathrm{~W}$ \\
Average tilt of slanted roof & $37^{\circ}$ & PV system price & $1300 € / \mathrm{kWp}$ \\
Stand. deviation of slanted roof tilt & $15^{\circ}$ & System investment per module $I_{m}$ & $305.50 €$ \\
Minimum surface area for PV & $15 \mathrm{~m}^{2}$ & Module costs share of investment & $48 \%$ \\
Module Technology & $\mathrm{c}-\mathrm{Si}$ & Operat. costs $r_{\text {oc }}$ share of investm. & $1 \%$ \\
Thermal coefficient $m$ & 0.036 & Yearly degradation $d$ & $0.5 \% \mathrm{a}^{-1}$ \\
Module width & $0.992 \mathrm{~m}$ & Interest rate $i$ & $5 \% \mathrm{a}^{-1}$ \\
Module height & $1.650 \mathrm{~m}$ & Overall reduction factor & $30 \%$ \\
\hline
\end{tabular}

Table A.1: Techno-economic assumptions on the characteristics of new PV systems. Cost factors are based on Wirth (2016).

$y=\left\{\begin{array}{lll}0, & \text { if } \theta \in\left[0,30^{\circ}\right) ; & { }_{1264} \\ 0.0006\left(\theta-30^{\circ}\right), & \text { if } \theta \in\left[30^{\circ}, 40^{\circ}\right) ; & { }_{1266} \\ 0.006+0.0012\left(\theta-40^{\circ}\right), & \text { if } \theta \in\left[40^{\circ}, 50^{\circ}\right) ; & { }_{1267} \\ 0.018+0.0029\left(\theta-50^{\circ}\right), & \text { if } \theta \in\left[50^{\circ}, 60^{\circ}\right) ; & { }_{1268} \\ 0.047+0.0068\left(\theta-60^{\circ}\right), & \text { if } \theta \in\left[60^{\circ}, 65^{\circ}\right) ; & \\ 0.081+0.0098\left(\theta-65^{\circ}\right), & \text { if } \theta \in\left[65^{\circ}, 70^{\circ}\right) ; & \\ 0.13+0.0166\left(\theta-70^{\circ}\right), & \text { if } \theta \in\left[70^{\circ}, 75^{\circ}\right) ; & { }_{1269} \\ 0.213+0.0276\left(\theta-75^{\circ}\right), & \text { if } \theta \in\left[75^{\circ}, 80^{\circ}\right) ; & { }_{1270} \\ 0.351+0.047\left(\theta-80^{\circ}\right), & \text { if } \theta \in\left[80^{\circ}, 85^{\circ}\right) ; & \\ & 1271 \\ 0.586+0.0828\left(\theta-85^{\circ}\right), & \text { if } \theta \in\left[85^{\circ}, 90^{\circ}\right) . & \end{array}\right.$

In order to account for shading from various obstacles, $G_{c}$ is linearly reduced beginning for $\theta_{Z}=$ $73^{\circ}$ and leading to a maximal reduction by $30 \%$ at $\theta_{Z}=90^{\circ}$ (Schubert, 2012).

A small fraction of the incoming irradiance is reflected off the surroundings onto the module and strongly depends on the albedo $\rho$ of the module's environment. In this paper, an isotropic approach is used to model the reflected irradiance $R_{c}$ setting $\rho=0.2$ (Quaschning, 2013),

$$
R_{c}=\frac{\rho}{2} \cdot G_{h} \cdot(1-\cos \beta) .
$$

To model the diffuse irradiance in plane of array $D_{c}$, the anisotropic approach of Perez et al. (1990) is used.

In the first step of the presented model, the sky's clearness $\varepsilon$ needs to be calculated with

$$
\varepsilon=\frac{\frac{D_{h}+B_{h}\left(\cos \theta_{Z}\right)^{-1}}{D_{h}}+\kappa \cdot \theta_{Z}^{3}}{1+\kappa \cdot \theta_{Z}^{3}},
$$


and a constant $\kappa=1.041$. Furthermore the sky's brightness $\Delta$ is defined by the air mass $A M, D_{h}$ and the normal extraterrestrial irradiance $I_{o}=1367 \frac{\mathrm{W}}{\mathrm{m}^{2}}$ :

$$
\Delta=A M \cdot \frac{D_{h}}{I_{o}} .
$$

The air mass $A M$ itself is defined as presented in Pickering (2002):

$$
A M=\frac{1}{\sin \left(90-\theta_{Z}+\frac{244}{165+47 \cdot\left(90-\theta_{Z}\right)^{1.1}}\right)},
$$

with $\theta_{Z}$ being given in degrees.

The calculated $\varepsilon$ can be classified into eight different classes of the sky's clearness and determines the parametrization of the coefficients $F_{11}, F_{12}, F_{13}$, $F_{21}, F_{22}$ and $F_{23}$ in accordance to Table B.2.

$F_{11-23}$ are then used together with $\varepsilon$ and $\Delta$ to calculate the circumsolar brightening coefficients $F_{1}$ and $F_{2}$ given by:

$$
\begin{aligned}
& F_{1}=F_{11}+F_{12} \cdot \Delta+F_{13} \cdot \theta_{Z}, \\
& F_{2}=F_{21}+F_{22} \cdot \Delta+F_{23} \cdot \theta_{Z} .
\end{aligned}
$$

\section{Appendix C. PV power simulation}

The global irradiance in plane of array $G_{c}$ as well ${ }_{1304}$ as the module temperature $T_{\text {mod }}$ strongly define the 1305
Coefficients for the transposition model of Perez et al.

\begin{tabular}{l|rrrrrr}
\hline$\varepsilon$ & $F_{11}$ & $F_{12}$ & $F_{13}$ & $F_{21}$ & $F_{22}$ & $F_{23}$ \\
\hline$[1,1.065)$ & -0.008 & 0.588 & -0.062 & -0.060 & 0.072 & -0.022 \\
{$[1.065,1.23)$} & 0.130 & 0.683 & -0.151 & -0.019 & 0.066 & -0.029 \\
{$[1.23,1.5)$} & 0.330 & 0.487 & -0.221 & 0.055 & -0.064 & -0.026 \\
{$[1.5,1.95)$} & 0.568 & 0.187 & -0.295 & 0.109 & -0.152 & -0.014 \\
{$[1.95,2.8)$} & 0.873 & -0.392 & -0.362 & 0.226 & -0.462 & 0.001 \\
{$[2.8,4.5)$} & 1.132 & -1.237 & -0.412 & 0.288 & -0.823 & 0.056 \\
{$[4.5,6.2)$} & 1.060 & -1.600 & -0.359 & 0.264 & -1.127 & 0.131 \\
{$[6.2,+\infty)$} & 0.678 & -0.327 & -0.250 & 0.156 & -1.377 & 0.251 \\
\hline
\end{tabular}

Table B.2: Coefficients which determine $F_{1}$ and $F_{2}$ depending on $\varepsilon$ (Perez et al., 1990).

power generation $P$ of a $\mathrm{PV}$ system. $T_{\text {mod }}$ is unknown but can be simulated out of the ambient temperature $T_{a m b}(\mathrm{SoDa}, 2017), G_{c}$ and a factor $m$ representing the thermal behavior of the individual construction:

$$
T_{m o d}=T_{a m b}+m \cdot G_{c},
$$

Within this paper, a value of $m=0.036$ is used, characterizing PV systems on top of the roof with a small roof-module distance of $<10 \mathrm{~cm}$ (Drews et al., 2007). The efficiency of the modules $\eta_{\text {mod }}$ can be calculated using the coefficients $k_{1}, \ldots, k_{6}$ from Table C.3 as well as $T_{\text {mod }}$ and $G_{c}$ :

$$
\begin{aligned}
\eta_{\text {mod }}=1 & +k_{1} \ln \frac{G_{c}}{G_{c, S T C}}+k_{2} \ln ^{2} \frac{G_{c}}{G_{c, S T C}} \\
& +\left(k_{3}+k_{4} \ln \frac{G_{c}}{G_{c, S T C}}+k_{5} \ln ^{2} \frac{G_{c}}{G_{c, S T C}}\right) \\
& \times\left(T_{\text {mod }}-T_{\text {mod }, S T C}\right) \\
& +k_{6}\left(T_{\text {mod }}-T_{\text {mod }, S T C}\right)^{2} .
\end{aligned}
$$

With STC being the Standard Test Conditions and defined by: 
Being able to simulate the efficiency of the modules in (C.2) and of the inverter in (C.5), the (nor-

$$
G_{c, S T C}=1000 \frac{W}{m^{2}}, \quad T_{m o d, S T C}=25^{\circ} \mathrm{C} .
$$

\begin{tabular}{r|rrr}
\multicolumn{4}{|c}{ PV module coefficients } \\
\hline & $\mathrm{c}-\mathrm{Si}$ & $\mathrm{CIS}$ & $\mathrm{CdTe}$ \\
\hline$k_{1}$ & -0.017162 & -0.005521 & -0.103251 \\
$k_{2}$ & -0.040289 & -0.038492 & -0.040446 \\
$k_{3}$ & -0.004681 & -0.003701 & -0.001667 \\
$k_{4}$ & 0.000148 & -0.000899 & -0.002075 \\
$k_{5}$ & 0.000169 & -0.001248 & -0.001445 \\
$k_{6}$ & 0.000005 & 0.000001 & -0.000023 \\
\hline
\end{tabular}

Table C.3: Coefficients of the PV power model Huld et al. (2010) for different technologies.
Since crystalline silicon cells clearly dominate the German PV market (Bührke and Wengenmayr, 2011), solely these are used within the simulation procedure. While the assumed PV modules have an efficiency of $14.4 \%$ under STC, the efficiencies that result from the consideration of ambient temperature, heating through irradiation etc. vary for each timestep during the year, but are usually lower. In Freiburg, the average efficiencies over the whole year range between $7.8 \%$ and $10.4 \%$ (depending on orientation).

In reality, an inverter is needed to transform the direct current from the modules into alternating current. Its efficiency $\eta_{i n v}$ mainly depends on the utilization $\rho_{D C}$

$$
\rho_{D C}=\eta_{\text {mod }} \cdot \frac{G_{c}}{G_{c, S T C}} .
$$

Finally, $\eta_{i n v}$ can be defined by specific coefficients $j_{1}=0.0079, j_{2}=0.0411$ and $j_{3}=0.0500$ derived from (Macêdo and Zilles, 2007):

$$
\eta_{i n v}=\frac{\rho_{D C}-\left(j_{1}+j_{2} \rho_{D C}+j_{3} \rho_{D C}^{2}\right)}{\rho_{D C}},
$$

\section{Appendix D. Screenshot of implementation}




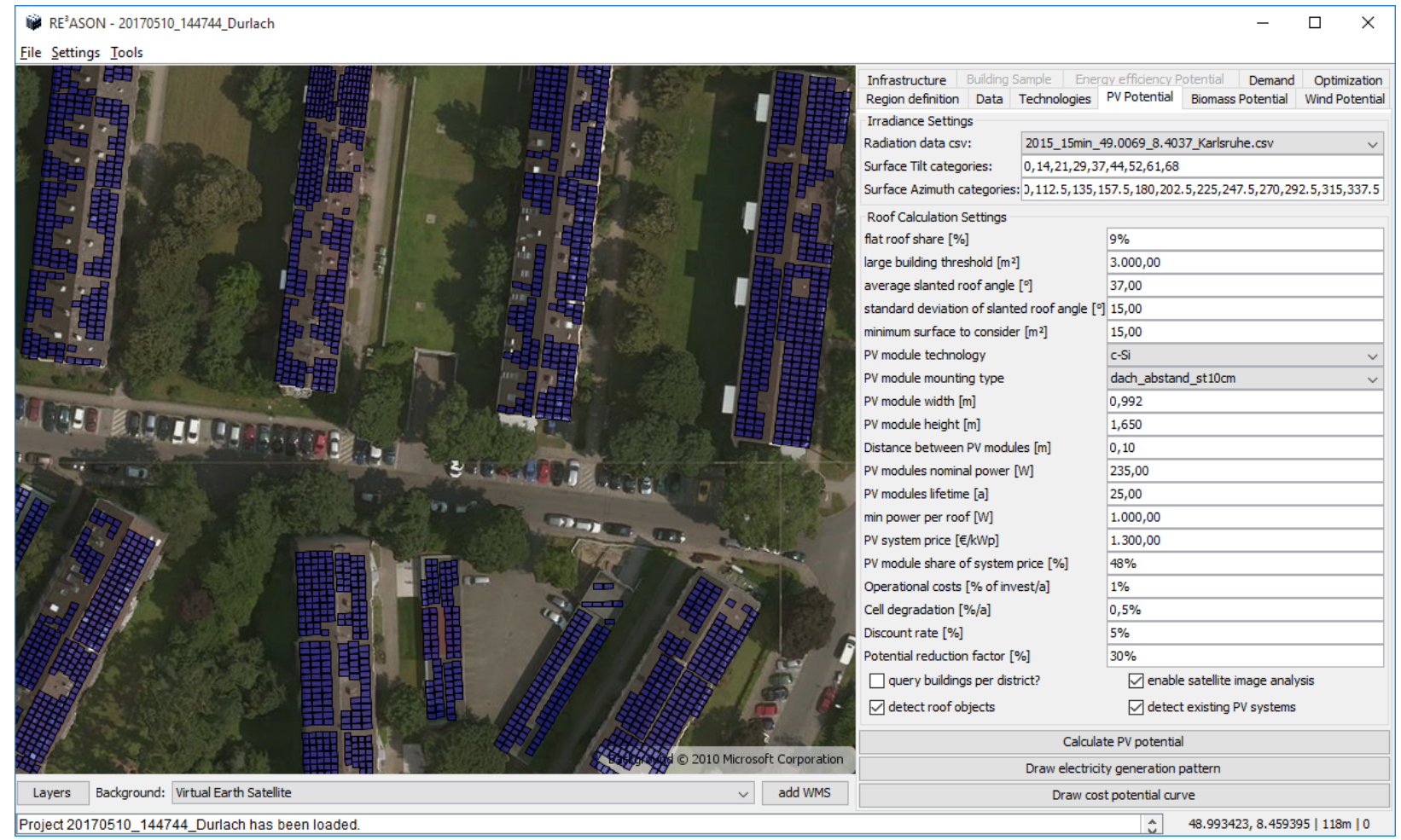

Figure D.12: Graphical user interface of the developed model framework. Source: Own depiction with image data from Bing Maps (Microsoft, 2016). 